\title{
The potential role of central obesity in male infertility: body mass index versus waist to hip ratio as they relate to selected semen parameters
}

\author{
Márton Keszthelyi ${ }^{1 *}$ (D, V. Anna Gyarmathy ${ }^{2,3}$, András Kaposi $^{4}$ and Zsolt Kopa ${ }^{5}$
}

\begin{abstract}
Background: Little is known about the potential role of central obesity among men. Our first aim was to confirm what is already known from prior research, namely that both BMI and WHR are inversely associated with selected semen parameters. Our second aim was to examine the potential role of central obesity by assessing if there was a difference between BMI and WHR regarding their relationships to these selected semen parameters.

Methods: In this cross-sectional study between January 2011 to January 2018, we analyzed semen samples from 1169 patients who visited an andrology clinic in Budapest for infertility reasons. Variables assessed were: body measurements (height, weight, waist circumference, and hip circumference), and the results of semen analysis (sperm concentration, total sperm count, progressive sperm motility, and normal sperm morphology).
\end{abstract}

Results: The mean height and weight were $180.6 \mathrm{~cm}$ and $87.3 \mathrm{~kg}$, respectively - the mean BMI was 26.8. The mean waist and hip circumferences were $100.9 \mathrm{~cm}$ and $94.8 \mathrm{~cm}$, respectively - the mean waist to hip ratio was 0.94 . The mean sperm concentration, total sperm count, and percents of progressive motility and normal morphology were $48.7 \mathrm{M} / \mathrm{ml}, 165$ million, 21.2, and 4.8\%, respectively. Both BMI and WHR were significant correlates in all semen parameter regression models. When comparing the parameter estimates for BMI with those for WHR for each semen parameter, the parameter estimate for WHR was significantly lower (indicating a stronger negative association) than that for BMI for progressive motility and total sperm count, but not for normal morphology or concentration.

Conclusions: Our study is the first to examine, using a large patient sample, the potential role of central obesity by comparing the difference between BMI and WHR as they relate to selected semen parameters. Our findings indicate a potential role of central obesity for progressive motility and total sperm count, but not for normal morphology and concentration. Despite the limitations and the exploratory nature of this study, we can conclude that our results point to a potential role of central obesity in male infertility, but this finding should be confirmed and further explored in future research.

Trial registration: The trial was retrospectively authorized after the data collection on September 24, 2018. Registration number: SE RKEB: 169/2018.

Keywords: Male infertility, Statistical modelling, Obesity, Body mass index, Waist to hip ratio

\footnotetext{
* Correspondence: keszthelyi.marton@med.semmelweis-univ.hu

${ }^{1}$ Department of Urology, Andrology Centre, Semmelweis University, Üllői út 78/b, Budapest 1082, Hungary

Full list of author information is available at the end of the article
}

(c) The Author(s). 2020 Open Access This article is licensed under a Creative Commons Attribution 4.0 International License, which permits use, sharing, adaptation, distribution and reproduction in any medium or format, as long as you give appropriate credit to the original author(s) and the source, provide a link to the Creative Commons licence, and indicate if changes were made. The images or other third party material in this article are included in the article's Creative Commons licence, unless indicated otherwise in a credit line to the material. If material is not included in the article's Creative Commons licence and your intended use is not permitted by statutory regulation or exceeds the permitted use, you will need to obtain permission directly from the copyright holder. To view a copy of this licence, visit http://creativecommons.org/licenses/by/4.0/. The Creative Commons Public Domain Dedication waiver (http://creativecommons.org/publicdomain/zero/1.0/) applies to the data made available in this article, unless otherwise stated in a credit line to the data. 


\section{Background}

An infertile relationship is defined by the World Health Organization (WHO) as the inability of a couple to achieve spontaneous pregnancy in 1 year despite being sexually active and non-contracepting [1]. Infertility is a serious health problem: in western developed countries about $15 \%$ of couples seek medical treatment because of infertility [2]. Several factors are known to be associated with both female and male fertility, including increased body weight [3-5]. For example, men who are overweight are more likely to have abnormal sperm characteristics, such as impairments in - among others sperm concentration, progressive motility, and normal morphology [6-14].

There are various ways to measure obesity. Body Mass Index (BMI), which is a person's weight in kilograms divided by the square of their height in meters, is the most frequently used marker [15]. The BMI, however, does not take into consideration certain factors, such as fat distribution and central obesity, which not only mark more precisely the overweight status, but have also been associated with health impairment [16]. The waist to hip ratio (WHR), which is the waist circumference divided by the hip circumference, however, takes into account the differences in body structure and has a proven to have more sensitivity in the prediction of several disease mortalities [17, 18].

Most studies that assessed the relationship between fertility and excess weight have relied on the BMI as a measure for overweight [19], and therefore little is known about the potential role of central obesity, which is better reflected by the WHR. Our study is designed to fill that gap in knowledge. Our first aim was to confirm what is already known from prior research, namely that both BMI and WHR are inversely associated with selected semen parameters. We chose sperm concentration, progressive motility, and normal morphology as semen parameters of interest because these sperm parameters indicate well the status of the sperm, from which we can assess fertility. Our second aim was to examine the potential role of central obesity by assessing if there was a difference between BMI and WHR regarding their relationships to these selected semen parameters. In other words, when BMI and WHR are standardized in order to become comparable with each other, any significant difference, favoring WHR, in the statistical parameters of their respective associations with any given semen parameter would indicate a role of central obesity.

\section{Methods}

Between January 2011 and January 2018 altogether 1188 patients visited an andrology clinic in Budapest, Hungary, for infertility reasons, providing altogether 1345 semen samples. Our center is a certified training center of the European Academy of Andrology and continuously takes part in various international quality control efforts. QuaDeGa and Gamete Expert Andrology Scheme are the running quality controls at our department.

This analysis used chart review of all these patients, which included the following variables: date of visit, date of birth, body measurements (height, weight, waist circumference, and hip circumference), and the results of semen analysis (sperm concentration, total sperm count, progressive sperm motility, and normal sperm morphology) according to current WHO criteria. Age was calculated by subtracting the date of birth from the date of visit.

\section{Body measurements}

Height was measured in centimeters with a standardized cloth tape measure. Patients were asked to remove shoes and stand erect with their shoulders relaxed and looking straight ahead. Weight was measured in kilograms using standardized digital scales. BMI was then calculated by dividing the weight in kilograms with the square of the height in meters $(\mathrm{kg} / \mathrm{m} 2)$. We measured the hip and waist circumference in centimeters according to the WHO 2011 guidelines by means of a constant $100 \mathrm{~g}$ tension providing tape [20]. Waist circumference was measured at the midpoint between the lower margin of the last palpable rib and the top of the iliac crest. Hip circumference was measured around the widest portion of the buttocks, with the tape parallel to the floor. WHR was then calculated by dividing the waist circumference measurement with the hip measurement $(\mathrm{W} \div \mathrm{H})$.

\section{Semen analysis}

Semen analysis was performed according to the WHO Laboratory Manual for the Examination and Processing of Human Semen 5th edition (2010) [1]. The "Who Laboratory manual for the Examination and processing of human semen" 2010 edition declares that to achieve best results for a standard semen analysis, the sample should be collected after a minimum of 2 days and a maximum of 7 days of sexual abstinence [1]. All our patients adhered our prescribed 3-5 days of abstinence.

From the standardized assessment sperm concentration, progressive sperm motility and normal sperm morphology were selected for further analysis. Sperm concentration was measured in million/milliliters (M/ $\mathrm{mL}$ ) by hemocytometer technique with Neubauer improved cell counting chamber. Diff-Quik ${ }^{\circ}$ stains were used to evaluate sperm progressive motility and normal morphology. The samples were assessed with 400x magnification on an Olympus CX21 microscope, and progressive motility and normal morphology are expressed as percentage of total cells. Computer-assisted sperm analysis (CASA Sperm Class Analyzer - Microptic 
Automatic Diagnostic System - Spain) was used on a Nikon Eclipse E200 microscope for the quality control of the data.

\section{Data management and statistical analysis}

The data were quality controlled for repeat visits, data entry errors, and influential outliers. Of the 1345 observations, 157 were removed because they were repeat visits, leaving a total of 1188 observations (equaling the first visits of all patients). Of these, one observation was removed because of missing values, and 18 were removed because of data entry errors. Then, loess local regression smooth curve fit plots were created with the proc. loess procedure in SAS V9.4. to visualize influential outliers. Based on this analysis, two observations were removed because they were influential outliers (for both patients, BMI $=54$ and $\mathrm{WHR}=1.0$ with respective large waist and hip circumferences). This analysis also confirmed that the relationships between semen parameters and BMI/WHR are linear. We further assessed our data in order to remove patients with clinical varicocele, orchiditis, epididymitis, and vesiculitis, but the final cleaned dataset did not contain any patients with these conditions. Therefore, the final study sample comprised of 1169 patient observations (98.4\% of all patients).

Patient semen parameters were compared by degree of obesity in the following groups: normal weight with BMI less than 25 (438 patients), overweight with BMI between 25 and 29.9 (510 patients) and obese with a BMI above 30 (221 patients), and WHR $<=0.9$ (361 patients) and WHR $>0.9$. Differences were evaluated with the Kruskal-Wallis non-parametric test.

To compare the regression slopes of the BMI vs. WHR models for each semen parameter, we standardized the BMI and WHR values to range from 0 to 1 using the proc. stdize procedure in SAS V9.4 with the method = range option. We chose this standardization method, because this strictly follows the original distribution of the original variable and makes the two different variables comparable. That means, if we plotted any parameter against either BMI or WHR, the plot with the original values would be identical to the plot with the standardized values, except for the value labels on the axis for BMI/WHR. As such, we included two $\mathrm{x}$ axes with our figures: one with the standardized values and one with the original values.

Univariate contingency tables to describe distribution and means procedures were conducted. After the removal of the influential outliers (as described above), the relationship between BMI and WHR, and semen parameters could be fitted as linear. Therefore, scatter plots were created with fitted linear regression lines in order to visualize the relationship between
BMI and WHR, and semen parameters. Univariate liner regression models adjusted for age (which is strongly associated both with BMI and WHR, and most likely with indicators for infertility as well) were created to calculate the regression line slope coefficients and their 95\% confidence intervals. For reference purposes, we are showing both non-standardized and standardized values for parameter estimates and their confidence intervals, standard errors, $\mathrm{t}$ values, $p$ values. For each semen parameter (dependent variable), $\mathrm{min} / \mathrm{max}$ line plots were created comparing the slope coefficients of BMI vs. WHR (independent variables) for that particular parameter. Statistically significant $(p<0.05)$ differences between the slopes were considered when the point estimate of the WHR slope coefficient fell outside of the 95\% confidence interval of the BMI slope coefficient [21]. SAS V9.4 software (SAS Institute Inc. Cary, NC) was used for data management and analysis, and data visualization.

\section{Results \\ Description of the sample}

Sample characteristics are presented in the Table 1. with means, SDs and data ranges. The mean age of the 1169 patients was 38.1 years. The mean height and weight were $180.6 \mathrm{~cm}$ and $87.3 \mathrm{~kg}$, respectively the mean BMI was 26.8. The mean waist and hip circumference were $100.9 \mathrm{~cm}$ and $94.8 \mathrm{~cm}$, respectively - the mean waist to hip ratio was 0.94 . The mean sperm concentration and total sperm count were 48.7 $\mathrm{M} / \mathrm{ml}$ and $164.9 \mathrm{M}$, respectively. The mean percent of progressive motility and normal morphology were $21.2 \%$ and 4.8 , respectively.

Table 2 shows mean, SD and range of sperm parameters by BMI and WHR categories and their significance testing. The figures show a decrease of semen parameter values with an increase of BMI and WHR categories.

\section{Results of regression procedures}

Both BMI and WHR were significant correlates in all age-adjusted semen parameter linear regression models (Table 3). Even though we adjusted for age, it was not significant in the context of concentration and progressive motility, only in the context of normal morphology (meaning higher age was associated with lower morphology values). When comparing the standardized parameter estimates for BMI with those for WHR for each semen parameter, the parameter estimate for WHR was significantly lower (indicating a stronger negative association) than that for BMI for progressive motility and total sperm count (Figs. 1 and 2), but not for concentration (Fig. 3 ) or normal morphology (Fig. 4). 
Table 1 Characteristics of the sample $(N=1169)$

\begin{tabular}{lll}
\hline Characteristic & mean (SD) & Range \\
\hline Participants & $38.1(7)$ & $17-67$ \\
Age & $180.6(7.5)$ & $155-210$ \\
Height & $87.3(15.9)$ & $55-183$ \\
Weight & $26.8(4.5)$ & $16.9-50$ \\
BMl & $100.9(8.9)$ & $56-149$ \\
Waist circumference & $94.8(12.4)$ & $59-165$ \\
Hip circumference & $0.94(0.07)$ & $0.63-1.22$ \\
Waist-to-hip ratio & & \\
Specimen & $3.6(1.8)$ & $0.1-12.0$ \\
Semen volume & $165.5(192.2)$ & $0-1270$ \\
Total sperm count & $48.7(55.7)$ & $0-681.5$ \\
Sperm concentration & $21.2(18.7)$ & $0-80$ \\
Progressive motility & $4.8(4.6)$ & $0-28$ \\
Normal morphology & $0.59(5.8)$ & $0-193.1$ \\
WBC & &
\end{tabular}

\section{Discussion}

This is the first study to examine, using a large patient sample, the potential role of central obesity by assessing the difference between BMI and WHR as they relate to selected semen parameters. Our study confirmed what has already been known from prior research: both BMI and WHR were inversely associated with our selected semen parameters. Furthermore, our finding that WHR had a significantly stronger negative association with progressive motility than BMI while there was no such difference for normal morphology and concentration indicates a potential role of central obesity for progressive motility but not for the latter two semen parameters.

While the role of central obesity in the decreased fertility rates of women has been well researched [22], little is known about the potential role of central obesity among men. As can be seen in the literature, both BMI and WHR are associated with some markers of infertility but not with others, and BMI and WHR are associated to different degrees with those parameters. For example, although the LIFE study assessed only waist circumference but not WHR, the results show a linear decline of ejaculate volume with increasing BMI and waist circumference, and it appears that the magnitude of the association is similar [23]. They further found that median sperm count was significantly associated with waist circumference but not with BMI, and that lower levels of concentration and sperm count were associated with both BMI and waist circumference. This suggests that there might be some kind of a factor that is specific to abdominal fat or some other characteristic related to waist circumference (and by extension, to WHR) that influences some but not all fertility markers. On the other hand, Fejes et al. showed that sperm count, total motile sperm count, and total progressive motile sperm count were associated with both waist circumference and hip circumference, but only the first two were associated with BMI and none with WHR [24]. However, their sample was very small $(n=81)$, and therefore the conclusions drawn from that study might be somewhat limited.

One review touched upon the potential role of abdominal fat on fertility and suggested that the correlation between WHR and sex steroids may not be a direct relationship, but rather the consequence of the shared covariance of total adiposity and WHR [25]. We believe, however, that BMI and WHR as correlates for certain fertility markers (such as progressive motility in our study) might differ, and they might do so for a number of reasons. For example, in males, about $80 \%$ of biologically available estrogen is produced by the aromatization

Table 2 Semen parameters distributed by the degree of obesity

\begin{tabular}{|c|c|c|c|c|c|c|c|}
\hline & \multicolumn{2}{|c|}{ Normal weight $\mathrm{BMI}<25(\mathrm{~N}=438)$} & \multicolumn{2}{|c|}{ overweight $25<\mathrm{BMl}<29.9(N=510)$} & \multicolumn{2}{|c|}{ obese $\mathrm{BMI}>30(N=221)$} & \multirow{2}{*}{$\begin{array}{l}\text { Kruskal-Wallis } \\
p \text {-value }\end{array}$} \\
\hline & Mean (SD) & Range & Mean (SD) & Range & Mean (SD) & Range & \\
\hline Sperm concentration (M/ml) & $49.6(50.14)$ & $0-295.25$ & $51.2(63.5)$ & $0-681.5$ & $41.1(45.7)$ & $0-256$ & 0.0362 \\
\hline Total sperm count (M) & $174.6(190.1)$ & $0-1014.3$ & $167.3(205.4)$ & $0-1270$ & 140.2(160.6) & $0-752.6$ & 0.0239 \\
\hline Progressive motility (\%) & $22.3(18)$ & $0-77.5$ & $20.9(19.4)$ & $0-80$ & $19.5(18.1)$ & $0-75$ & 0.0582 \\
\hline \multirow[t]{3}{*}{ Normal morphology (\%) } & $4.9(4.2)$ & $0-21.5$ & $4.9(4.9)$ & $0-28$ & $4.3(4.3)$ & $0-19.5$ & 0.0455 \\
\hline & \multicolumn{2}{|c|}{$W H R=<0.9(N=361)$} & \multicolumn{2}{|c|}{ WHR $>0.9(N=808)$} & \multicolumn{2}{|l|}{ Kruskal-Wallis } & \\
\hline & Mean (SD) & Range & Mean (SD) & Range & $p$-value & & \\
\hline Sperm concentration (M/ml) & $56.3(56.9)$ & $0-340$ & $45.3(54.9)$ & $0-681.5$ & 0.0001 & & \\
\hline Total sperm count (M) & $201.1(216)$ & $0-1087.2$ & $148.75(178.3)$ & $0-1270$ & $<.0001$ & & \\
\hline Progressive motility (\%) & $24.2(19.1)$ & $0-80$ & 19.9(18.3) & $0-80$ & 0.0002 & & \\
\hline Normal morphology (\%) & $5.3(4.9)$ & $0-24$ & 4.6(4.4) & $0-28$ & 0.0672 & & \\
\hline
\end{tabular}


Table 3 Linear regression results for both non-standradized and standarzied BMI and WHR values

\begin{tabular}{|c|c|c|c|c|c|c|}
\hline \multirow{2}{*}{$\begin{array}{l}\text { Non-standarzied } \\
\text { Variable }\end{array}$} & Parameter & \multicolumn{2}{|c|}{ 95\% Confidence Limits } & Standard & t Value & $\operatorname{Pr}>|t|$ \\
\hline & \multicolumn{3}{|l|}{ Estimate } & \multicolumn{3}{|l|}{ Error } \\
\hline \multicolumn{7}{|l|}{ Concentration } \\
\hline BMl & -0.91 & -1.65 & -0.18 & 0.37 & -2.45 & 0.01 \\
\hline age & 0.19 & -0.27 & 0.66 & 0.24 & 0.82 & 0.41 \\
\hline WHR & -84.93 & -131.71 & -38.15 & 23.84 & -3.56 & 0.00 \\
\hline age & 0.24 & -0.23 & 0.70 & 0.24 & 1.00 & 0.32 \\
\hline \multicolumn{7}{|l|}{ Progressive motility } \\
\hline BMI & -0.32 & -0.56 & -0.07 & 0.12 & -2.56 & 0.01 \\
\hline age & -0.11 & -0.27 & 0.04 & 0.08 & -1.43 & 0.15 \\
\hline WHR & -33.99 & -49.59 & -18.40 & 7.95 & -4.28 & $<.0001$ \\
\hline age & -0.09 & -0.25 & 0.06 & 0.08 & -1.15 & 0.25 \\
\hline \multicolumn{7}{|l|}{ Normal morphology } \\
\hline BMI & -0.07 & -0.13 & -0.01 & 0.03 & -2.15 & 0.03 \\
\hline age & -0.04 & -0.08 & 0.00 & 0.02 & -2.09 & 0.04 \\
\hline WHR & -4.49 & -8.32 & -0.65 & 1.95 & -2.30 & 0.02 \\
\hline age & -0.04 & -0.08 & 0.00 & 0.02 & -2.09 & 0.04 \\
\hline \multicolumn{7}{|l|}{ Total sperm count } \\
\hline BMI & -3.62 & -6.14 & -1.09 & 1.29 & -2.81 & 0.01 \\
\hline age & 0.05 & -1.55 & 1.66 & 0.82 & 0.07 & 0.95 \\
\hline WHR & -409.00 & -569.64 & -248.36 & 81.87 & -5.00 & $<.0001$ \\
\hline age & 0.36 & -1.24 & 1.95 & 0.81 & 0.44 & 0.66 \\
\hline \multirow[t]{2}{*}{ Standardized Variable } & Parameter & \multicolumn{2}{|c|}{ 95\% Confidence Limits } & Standard & t Value & $\operatorname{Pr}>|t|$ \\
\hline & Estimate & & & Error & & \\
\hline \multicolumn{7}{|l|}{ Concentration } \\
\hline sBMI & -30.25 & -54.45 & -6.05 & 12.34 & -2.45 & 0.01 \\
\hline age & 0.19 & -0.27 & 0.66 & 0.24 & 0.82 & 0.41 \\
\hline sWHR & -49.69 & -77.05 & -22.32 & 13.95 & -3.56 & 0.00 \\
\hline age & 0.24 & -0.23 & 0.70 & 0.24 & 1.00 & 0.32 \\
\hline \multicolumn{7}{|l|}{ Progressive motility } \\
\hline sBMI & -10.55 & -18.63 & -2.46 & 4.12 & -2.56 & 0.01 \\
\hline age & -0.11 & -0.27 & 0.04 & 0.08 & -1.43 & 0.15 \\
\hline sWHR & -19.89 & -29.01 & -10.77 & 4.65 & -4.28 & $<.0001$ \\
\hline age & -0.09 & -0.25 & 0.06 & 0.08 & -1.15 & 0.25 \\
\hline \multicolumn{7}{|l|}{ Normal morphology } \\
\hline sBMI & -2.17 & -4.15 & -0.19 & 1.01 & -2.15 & 0.03 \\
\hline age & -0.04 & -0.08 & 0.00 & 0.02 & -2.09 & 0.04 \\
\hline sWHR & -2.63 & -4.87 & -0.38 & 1.14 & -2.30 & 0.02 \\
\hline age & -0.04 & -0.08 & 0.00 & 0.02 & -2.09 & 0.04 \\
\hline
\end{tabular}

of testosterone outside the testes, primarily in the subcutaneous abdominal fat tissues [23, 26]. In addition, there might be other, thus far unknown roles of the abdominal fat in male fertility, leading to infertility in case of excess central adiposity in overweight individuals.
Therefore, the importance of the distinction between BMI and WHR lies in that if there is no difference in their associations with certain fertility markers, then general weight loss might improve those markers. However, if the association is stronger for WHR than for 


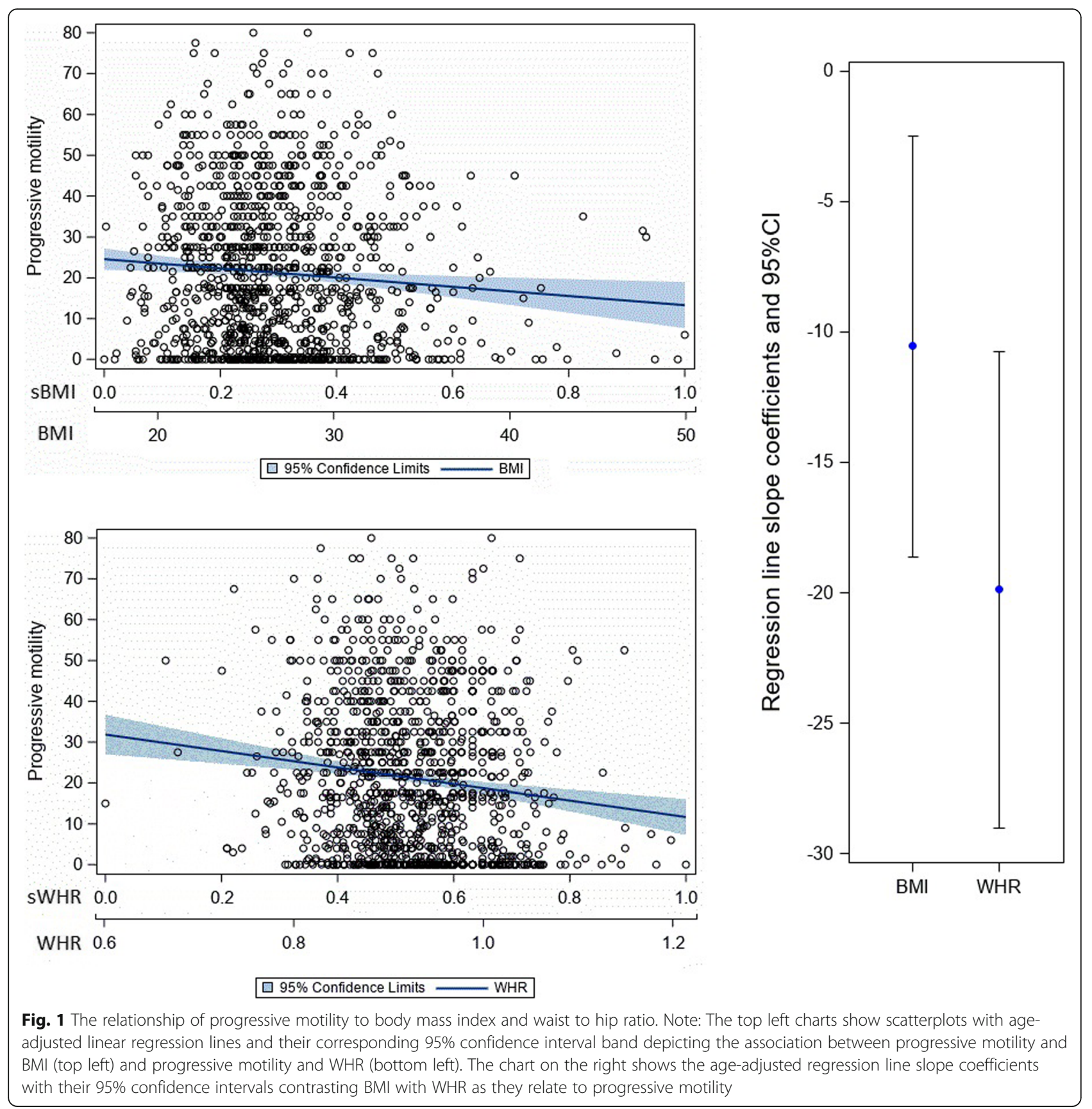

BMI for other fertility markers, then longitudinal studies should investigate this cross-sectional finding. If longitudinal studies yield similar results, then specific strategies to reduce central adiposity might be needed in addition to general weight loss to improve those particular fertility markers - such as, potentially, progressive motility.

One limitation of our study is that we did not assess ejaculate volume. The reason for this is because we consider ejaculate volume as a secondary indicator of fertility, since the indicators regarding quality of the sperm, more specifically the concentration, progressive motility, and normal morphology are considered more important for fertility than ejaculate volume [27]. Although abstinence time in general is an influence factor for semen quality parameters, we did not add this variable to our analysis, since all patients in this study had a by the WHO prescribed optimal, and virtually the same abstinence time (3-5 


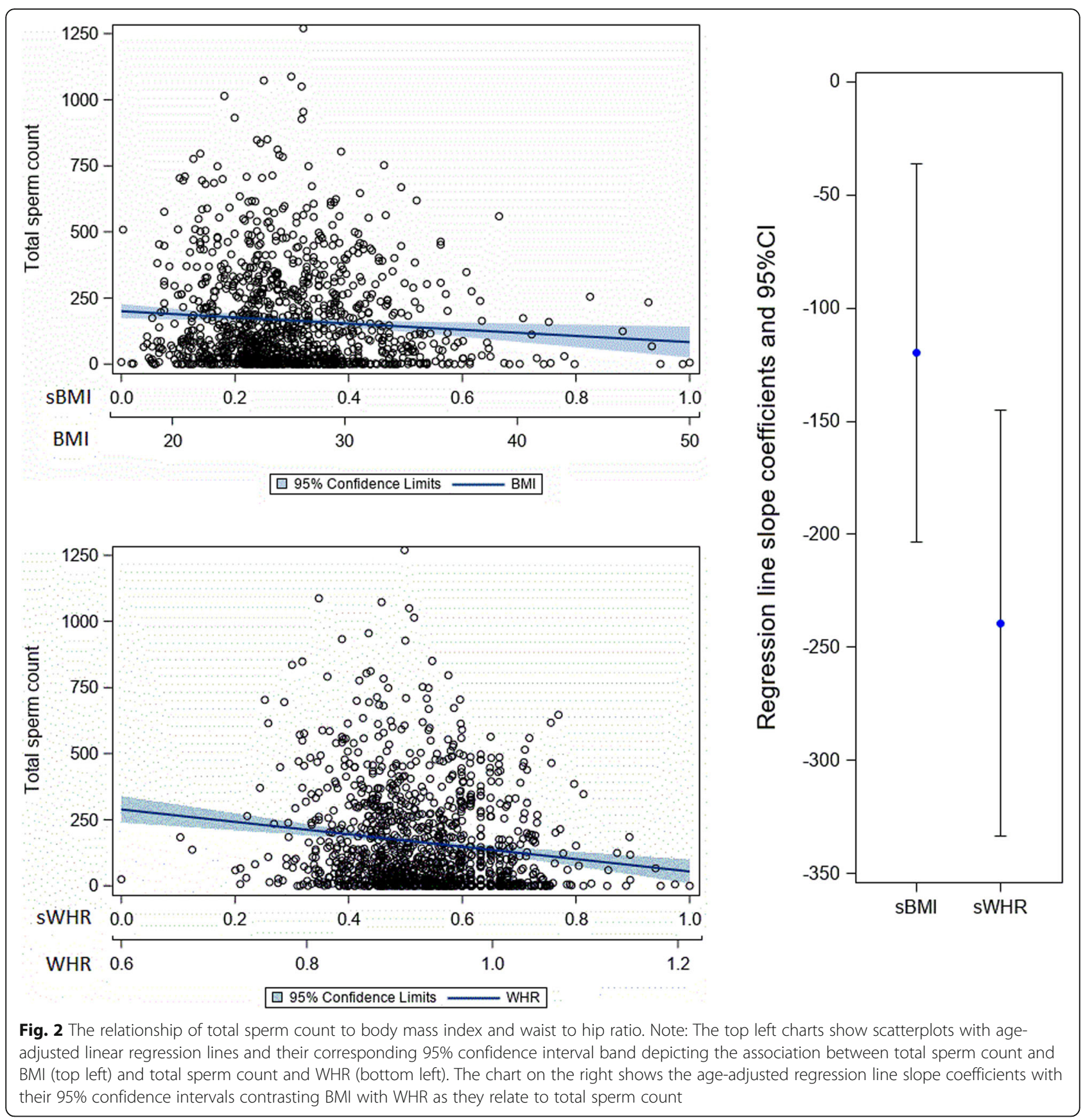

days). As a matter of fact, systematic review by Hanson et al. found that semen parameters are lower before and abstinence of 3 days and higher after 5 days, but within 3 and 5 those parameters are not different [28]. Another limitation is that, since this is an exploratory study comparing BMI with WHR, we did not assess any other biological markers besides the selected fertility characteristics, or any other potential control variables besides age. Likewise, we did not control for other factors that might affect semen parameters, including but not limited to previous varicocele; hormonal, congenital, or structural abnormalities; any obvious forms of partial obstruction, or medications. However, our final dataset did not contain any patients with such conditions, and many personal background and lifestyle variables had no or just marginally significant relationship with semen parameters in prior studies [29]. Additionally, while 


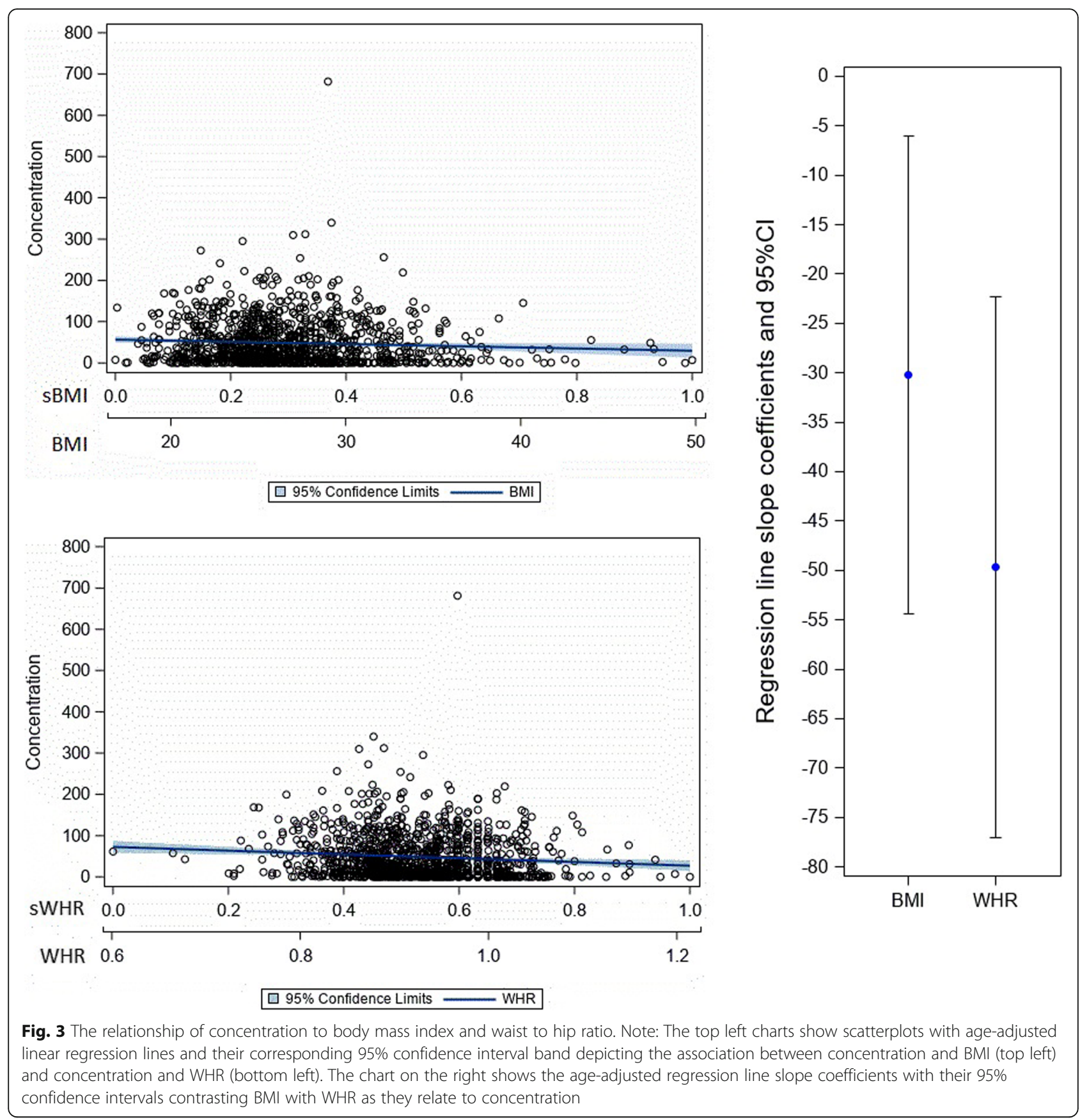

these potential control variables may influence the relationship between sperm characteristics and either BMI or WHR, their influence will most probably be very similar on them. Moreover, numerous lifestyle factors in addition to smoking and alcohol consumption, such as use of drugs, anabolic steroids, doping, physical activity, working conditions, stress and worked hours per day might adversely affect male fertility. In our study no information about subject's smoking or alcohol consumption were available. Although a recent review article about the relationship between infertility and lifestyle characteristics such as smoking and alcohol intake [30] found no evidence that either alcohol or smoking would influence semen quality and therefore ART therapy among infertile men, further studies should explore this. This suggests that while certain lifestyle factors might be influential among males in the general population, those might not apply to the special population of infertile men - the study population in our manuscript - whose infertility reasons might be 


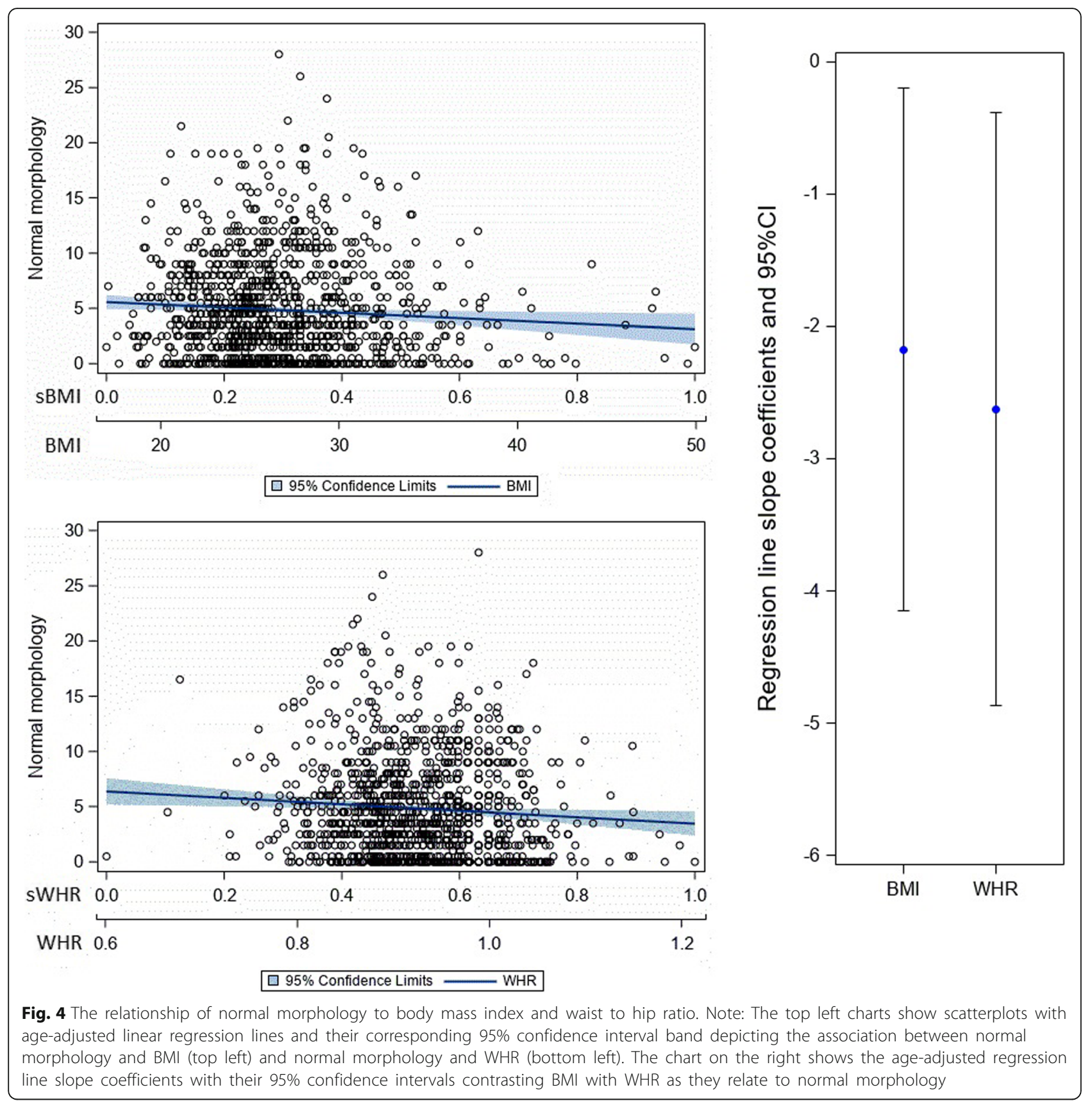

complexly multifaceted. Given this and the fact that the aim of our analysis was to assess the potential impact of central obesity on fertility and thus the relationship between the waist-to-hip ratio and the BMI, controlling our results for these parameters would have unnecessarily complicated statistical analysis without much added benefit. Still, future studies might explore this further - by also adding other variables that have significant, and potentially confounding relationship with fertility markers - to control for any potential confounding.

\section{Conclusions}

Our study the first to examine, using a large patient sample, the potential role of central obesity by comparing the difference between BMI and WHR as they relate to selected semen parameters. Our findings indicate a potential role of central obesity for progressive motility but not for normal morphology and concentration. Despite the limitations and the exploratory nature of this study, we can conclude that our results point to a potential role of central obesity in male infertility, but this finding should be confirmed and further explored in future research. 


\section{Abbreviations}

BMl: Body Mass Index; WHO: World Health Organization; WHR: Waist to Hip Ratio

\section{Acknowledgements}

This analysis was presented at the 12th congress of the Hungarian Andrology Society, where it received a special recognition as the "Highest scientific quality presentation".

\section{Authors' contributions}

M. K. participated in the design of the analysis, performed data management and literature review, and wrote the paper. V. A. G. designed the analysis, performed some statistical analysis, created the figures, contributed to writing the paper, and provided advice. A. K. contributed to the design of the analysis and the writing of the paper and performed statistical analysis. Z. K. designed and supervised the data collection of the study and contributed to the writing of the paper. All authors read and approved the final manuscript as submitted.

\section{Funding}

This research was supported by Semmelweis University, School of Ph.D. Studies grant number EFOP-3.6.3-VEKOP-16-2017-00009, covering the works expenses related to investigative activities including data collection, analysis, interpretation, and publication. The funders had no role in study design, data collection and analysis, decision to publish, or preparation of the manuscript. Open access funding provided by Semmelweis University.

\section{Availability of data and materials}

The datasets used and/or analyzed during the current study are available from the corresponding author on reasonable request.

\section{Ethics approval and consent to participate}

The informed consent obtained from study participants was written and approved by the ethical committee of Semmelweis University. Semmelweis University Regional and Institutional Committee of Science and Research Ethics, SE RKEB No: 169/2018.

\section{Consent for publication}

Not applicable.

\section{Competing interests}

V. Anna Gyarmathy is an Associate Editor at BMC Public Health.

\section{Author details}

'Department of Urology, Andrology Centre, Semmelweis University, Üllői út 78/b, Budapest 1082, Hungary. ${ }^{2}$ EpiConsult LLC, 8 The Green, STE A, Dover, DE 19904, USA. ${ }^{3}$ Johns Hopkins Bloomberg School of Public Health, Baltimore, 615 N Wolfe St, Baltimore, MD 21205, USA. ${ }^{4}$ Department of Biophysics and Radiation Biology, Semmelweis University, Túzoltó u. 37-47, Budapest 1094, Hungary. ${ }^{5}$ Department of Urology, Andrology Centre, Semmelweis University, Üllői út 78/b, Budapest 1082, Hungary.

Received: 10 August 2019 Accepted: 26 February 2020

\section{Published online: 12 March 2020}

\section{References}

1. World Health Organization. WHO laboratory manual for the examination and processing of human semen. 5th ed; 2010.

2. Arow JP, Sharlip ID, Belker AM, Lipshultz LI, Sigman M, Thomas AJ, et al. Male infertility best practice policy committee of the American Urological Association Inc: best practice policies for male infertility. J Urol. 2010;167:2138-44.

3. Jensen TK, Andersson AM, Jorgensen N, Andersen AG, Carlsen E, Petersen $J \mathrm{H}$, et al. Body mass index in relation to semen quality and reproductive hormones among 1558 Danish men. Fertil Steril. 2004;82:863-70.

4. Pasquali R, Patton L, Gambineri A. Obesity and infertility. Curr Opin Endocrinol Diabetes Obes. 2007;14:482-7.

5. Sharma R, Harlev A, Agarwal A, Esteves SC. Cigarette Smoking and Semen Quality: A New Meta-analysis Examining the Effect of the 2010 World Health Organization Laboratory Methods for the Examination of Human Semen. Eur Urol. 2016;70:635-45.

6. Du Plessis SS, Cabler S, McAlister DA, Sabanegh E, Agarwal A. The effect of obesity on sperm disorders and male infertility. Nat Rev Urol. 2010;7:153-61.
7. Bonde JP, Ernst E, Jensen TK, Hjollund NH, Kolstad H, Henriksen TB, et al. Relation between semen quality and fertility: a population-based study of 430 first-pregnancy planners. Lancet. 1998;352:1172-7.

8. Slama R, Eustache F, Ducot B, Jensen TK, Jorgensen N, Horte A, et al. Time to pregnancy and semen parameters: a cross-sectional study among fertile couples from four European cities. Hum Reprod. 2002;17:503-15.

9. Guzick DS, Overstreet JW, Factor-Litvak P, Brazil CK, Nakajima ST, Coutifaris C, et al. Sperm morphology, motility, and concentration in fertile and infertile men. N Engl J Med. 2001;345:1388-93.

10. Oliveira JBA, Petersen CG, Mauri AL, Vagnini LD, Renzi A, Petersen B, et al. Association between body mass index and sperm quality and sperm DNA integrity. A large population study. Andrologia. 2018;50:12889.

11. Engin-Ustun Y, Yılmaz N, Akgun N, Aktulay A, Tuzluoğlu AD, Bakırarar B. Body Mass Index Effects Kruger's Criteria in Infertile Men. Int J Fertil Steril. 2018;11:258-62.

12. Alshahrani S, AhmedAF GAH, Abalhassan M, Ahmad G. The impact of body mass index on semen parameters in infertile men. Andrologia. 2016:48:1125-9.

13. Tsao CW, Liu CY, Chou YC, Cha TL, Chen SC, Hsu CY. Exploration of the Association between Obesity and Semen Quality in a 7630 Male Population. PLOS One. 2015:10:0119458.

14. Hong Z, Bin C, Hongxiang W, Kai H, Yan J, Hao Y, et al. Association of body mass index with semen parameters and hormonal profile among infertile males. Chin J Androl. 2014;28:36-9.

15. Ortega FB, Sui X, Lavie CJ, Blair SN. Body Mass Index, the Most Widely Used but also Widely Criticized Index: Would a Gold-Standard Measure of Total Body Fat be a Better Predictor of Cardiovascular Disease Mortality? Mayo Clin Proc. 2016;91:443-55.

16. Wu S, Wang R, Jiang A, Ding Y, Wu M, Ma X, et al. Abdominal obesity and its association with health-related quality of life in adults: a populationbased study in five Chinese cities. Health Qual Life Outcomes. 2014;12:100.

17. Price GM, Uauy R, Breeze E, Bulpitt CJ, Fletcher AE. Weight, shape, and mortality risk in older persons: elevated waist-hip ratio, not high body mass index, is associated with a greater risk of death. Am J Clin Nutr. 2006:84: $449-60$

18. Mørkedal B, Romundstad PR, Vatten LJ. Informativeness of indices of blood pressure, obesity and serum lipids in relation to ischaemic heart disease mortality: the HUNT-II study. Eur J Epidemiol. 2011;26:457-61.

19. Kasturi SS, Tannir J, Brannigan RE. The Metabolic Syndrome and Male Infertility. J Androl. 2008;29:251-9.

20. World Health Organization. Waist circumference and waist-hip ratio, report of a WHO expert consultation. 2008.

21. Gyarmathy VA, Johnston LG, Caplinskiene I, Caplinskas S, Latkin CA. A simulative comparison of respondent driven sampling with incentivized snowball sampling - The "strudel effect". Drug Alcohol Depend. 2014;135:71-7.

22. Willis D, Mason H, Gilling-Smith C, Franks S. Modulation by insulin of folliclestimulating hormone and luteinizing hormone actions in human granulosa cells of normal and polycystic ovaries. J Clin Endocrinol Metab. 1996;81:302-9.

23. Eisenberg ML, Kim S, Chen Z, Sundaram R, Schisterman EF, Buck Louis GM. The relationship between male $\mathrm{BMI}$ and waist circumference on semen quality: data from the LIFE study. Hum Reprod. 2014;29:193-200.

24. Fejes I, Koloszár S, Szöllősi J, Závaczki Z, Pál A. Is semen quality affected by male body fat distribution? Andrologia. 2005;37:155-9.

25. Pasquali R. Obesity, fat distribution and infertility. Maturitas. 2006;54:363-71.

26. Vermeulen A, Kaufman JM, Goemaere S, van Pottelberg I. Estradiol in elderly men. Aging Male. 2002:5:98-102.

27. Bostofte E, Serup J, Rebbe H. Relation between sperm count and semen volume, and pregnancies obtained during a twenty-year follow-up period. Int J Androl. 1982;5:267-75.

28. Hanson BM, Aston KI, Jenkins TG, Carrell DT, Hotaling JM. The impact of ejaculatory abstinence on semen analysis parameters: a systematic review. J Assist Reprod Genet. 2018:35(2):213-20.

29. Hammiche F, Laven JSE, Twigt JM, Boellaard WPA, Steegers EAP, SteegersTheunissen RP. Body mass index and central adiposity are associated with sperm quality in men of subfertile couples. Hum Reprod. 2012;27:2365-72.

30. Mínguez-Alarcón L, Chavarro JE, Gaskins AJ. Caffeine, alcohol, smoking, and reproductive outcomes among couples undergoing assisted reproductive technology treatments. Fertil Steril. 2018;110(4):587-92.

\section{Publisher's Note}

Springer Nature remains neutral with regard to jurisdictional claims in published maps and institutional affiliations. 